\title{
Consumptive and nonconsumptive effects of cannibalism in fluctuating age-structured populations
}

\author{
Scott A. Wissinger, ${ }^{1,2,5}$ Howard H. Whiteman, ${ }^{2,3}$ Mathieu Denoël, ${ }^{2,4}$ Miranda L. Mumford, ${ }^{1,2}$ \\ and Catherine B. Aubee 2,3 \\ ${ }^{1}$ Biology Department, Allegheny College, Meadville, Pennsylvania 16335 USA \\ ${ }^{2}$ Rocky Mountain Biological Laboratory, P.O. Box 519, Crested Butte, Colorado 81224 USA \\ ${ }^{3}$ Department of Biological Sciences, Murray State University, Murray, Kentucky 42071 USA \\ ${ }^{4}$ Behavioural Biology Unit, Department of Environmental Sciences, University of Liège, 4020 Liège, Belgium
}

\begin{abstract}
Theory and empirical studies suggest that cannibalism in age-structured populations can regulate recruitment depending on the intensity of intraspecific competition between cannibals and victims and the nature of the cannibalism window, i.e., which size classes interact as cannibals and victims. Here we report on a series of experiments that quantify that window for age-structured populations of salamander larvae and paedomorphic adults. We determined body size limits on cannibalism in microcosms and then the consumptive and nonconsumptive (injuries, foraging and activity, diet, growth) effects on victims in mesocosms with seminatural levels of habitat complexity and alternative prey. We found that cannibalism by the largest size classes (paedomorphs and $\geq$ age $3+$ yr larvae) occurs mainly on young-of-the-year (YOY) victims. Surviving YOY and other small larvae had increased injuries, reduced activity levels, and reduced growth rates in the presence of cannibals. Data on YOY survival in an experiment in which we manipulated the density of paedomorphs combined with historical data on the number of cannibals in natural populations indicate that dominant cohorts of paedomorphs can cause observed recruitment failures. Dietary data indicate that ontogenetic shifts in diet should preclude strong intraspecific competition between YOY and cannibals in this species. Thus our results are consistent with previous empirical and theoretical work that suggests that recruitment regulation by cannibalism is most likely when YOY are vulnerable to cannibalism but have low dietary overlap with cannibals. Understanding the role of cannibalism in regulating recruitment in salamander populations is timely, given the widespread occurrences of amphibian decline. Previous studies have focused on extrinsic (including anthropogenic) factors that affect amphibian population dynamics, whereas the data presented here combined with long-term field observations suggest the potential for intrinsically driven population cycles.
\end{abstract}

Key words: age structure; Ambystoma tigrinum nebulosum; cannibalism; consumptive and nonconsumptive effects; Mexican Cut Nature Preserve, Colorado, USA; population fluctuations; recruitment failure; tiger salamanders.

\section{INTRODUCTION}

Cannibalism is widespread in nature (Fox 1975, Polis 1981, Elgar and Crespi 1992, Woodward and Hildrew 2002), especially in size-structured populations where it has consequences for community and food web dynamics (Woodward et al. 2005, Rudolf 2007a, b, 2008) and population regulation (e.g., Diekmann et al. 1986, Hastings and Constantino 1991, Claessen et al. 2004, Persson et al. 2004a, b). When cannibals and victims are in different year classes or life stages (e.g., adults and larvae), dominant cohorts of cannibals can regulate recruitment (Gaines and Roughgarden 1985, Hastings and Constantino 1987, McCauley and Murdoch 1987,

Manuscript received 22 July 2008; revised 7 January 2009; accepted 8 April 2009; final version received 28 May 2009. Corresponding Editor: A. S. Flecker.

${ }^{5}$ E-mail: swissing@allegheny.edu
Van Buskirk 1992). Negative density dependence and recruitment regulation by cannibalism have been best studied in Tribolium beetles (Park et al. 1965, Mertz 1972, Benoît et al. 1998) and predatory fishes (Donovan et al. 1997, Juanes 2003, Post 2003, Andersson et al. 2007). In both cases, whether cannibalism stabilizes or destabilizes populations depends on an interplay between the positive effects on cannibal growth and fecundity and negative effects on victim survival and growth (Hastings and Constantino 1991, Claessen and de Roos 2003, Persson et al. 2004a). That interplay depends in part on the strength of competition between cannibals and victims (de Roos and Persson 2003) and in part on the size window of vulnerability; i.e., the size thresholds that determine which age classes interact as cannibals and victims (Claesson et al. 2004). Although knowing the bounds on this window is fundamental for predicting the population-level consequences of canni- 
balism, they are often poorly documented (Claesson et al. 2004).

Most studies on cannibalism focus on consumptive effects on victims. However, the threat of cannibalism can have nonconsumptive effects (sensu Abrams 2007) on victim activity, foraging, and refuge use (Polis 1980, Sih 1982, Leonardsson 1991, Van Buskirk 1992, Persson and Eklöv 1995, Claus-Walker et al. 1997, Biro et al. 2003, Rudolf 2006). Cannibal-induced changes in behavior can reduce victim growth and survival and hence should also affect population dynamics (Peckarsky et al. 2008). For example, in dragonfly populations with three age classes, nonconsumptive effects of the oldest year class were stronger on the adjacent than on the smallest year class, thus explaining the two-year cycles of year class dominance observed in natural ponds (Van Buskirk 1992). Injuries that result from cannibals will also affect victim survival and growth and hence population dynamics (Harris 1989, Van Buskirk and Smith 1991). Although nonconsumptive effects of predators can be as or more important than consumptive effects (Lima and Dill 1990, Werner and Peacor 2003, Sih 2004, Peckarsky et al. 2008), there are relatively few studies that have experimentally quantified both of these effects of cannibalism in long-lived species with age-structured populations.

In this paper we report on consumptive and nonconsumptive effects of cannibalism in age-structured populations of tiger salamanders (Ambystoma tigrinum nebulosum). At low elevations, metamorphosis to the terrestrial adult stage occurs after one season of larval growth; thus, size structure and cannibalism occur within cohorts and are often facilitated by the polyphenic development of "typical larvae" vs. "cannibalistic morphs" (Collins 1981, Maret and Collins 1997, Whiteman et al. 2003, Denoël et al. 2006). In contrast, at high elevations, short growing seasons and cool temperatures retard larval development so that metamorphosis to the terrestrial adult stage is delayed until the third or fourth summer (= age $2+$ yr and 3+ yr larvae) (Sprules 1974, Sexton and Bizer 1978). Slowly growing individuals that do not reach the minimum size for metamorphosis by the fourth year remain in ponds where they mature as long-lived (10-20 years) paedomorphic (larval morphology) adults (Whiteman 1994). High-elevation populations in the western United States contain 10+ year classes of salamanders that are the top predators in ponds and fishless lakes (Wissinger et al. 1999a, $b$, Whiteman and Wissinger 2005).

Annual mark-recapture censuses at our main study site document salamander population fluctuations that are not correlated with interannual variation in climate, nor coupled with the abundances of other species (predators, prey, parasites, pathogens) (Wissinger and Whiteman 1992, Whiteman and Wissinger 2005). Instead, these fluctuations are associated with interannual variation in the survival of young-of-the-year (YOY) larvae (Whiteman and Wissinger 2005). The purpose of the experiments reported here was to determine the potential role(s) of cannibalism in these recruitment failures. Specifically, our goals were to (1) establish whether paedomorphs and large larvae (age $\geq 3+$ yr) actually cannibalize YOY and other small size classes of conspecifics under seminatural conditions of habitat complexity and alternative prey, (2) explore the size windows for the consumptive and nonconsumptive effects of cannibals on potential victims, and (3) quantify the relationship between cannibal densities and victim survival in order to make inferences about the number of paedomorphs required to eliminate recruitment. Understanding the factors that underlie population fluctuations in amphibians is of timely importance for understanding the causes of natural population fluctuations and distinguishing them from those associated with human-induced amphibian declines (Houlahan et al. 2000, Alford et al. 2001, Kiesecker et al. 2001, Collins and Storfer 2003, Skelly et al. 2003).

\section{Methods}

\section{Size constraints on the potential for cannibalism}

The experiments were conducted in central Colorado, USA, at the Mexican Cut Nature Preserve (elevation 3400-3600 m), a remote wilderness site owned by The Nature Conservancy and managed for research by the Rocky Mountain Biological Laboratory (site description in Wissinger et al. [1999a]; photographs in Appendix A). To determine the range of victim body sizes that would be of interest to study in the mesocosms, we first conducted short-term (72 h) experiments in microcosms $\left(0.25-\mathrm{m}^{2}\right.$ bottom area plastic storage containers; $15-\mathrm{cm}$ water depth; $2.5-\mathrm{cm}$ detrital substrate depth). Microcosms were housed in a portable field laboratory located adjacent to the ponds. Small invertebrates were retained in the detritus as a prey base, but large predators such as beetles and odonate larvae were removed. For each size combination, two potential victims were introduced into each microcosm and allowed to acclimate for $24 \mathrm{~h}$, after which the potential cannibal was introduced. Potential cannibals were held separately without prey for $24 \mathrm{~h}$ prior to introduction to standardize hunger levels. Neither potential cannibals nor victims were reused across trials. For each combination, we conducted five replicates with and five without the potential cannibal. In 2002, we combined paedomorphs with three year classes of larvae (ages 1+, 2+, and 3+ yr), and three size classes of YOY that corresponded to sizes typically found in July, August, and September, respectively. In 2003 we repeated the experiments with age $\geq 3+$ yr larvae as potential cannibals on YOY, age $1+\mathrm{yr}$, and age $2+\mathrm{yr}$ larvae. Size data for all combinations are given in Appendix B. Because of the nonnormal nature of the data, we used Mann-Whitney $U$ tests to compare survival of victims with and without cannibals. 


\section{Consumptive and nonconsumptive effects of cannibalism under seminatural conditions}

The results of the microcosm experiments allowed us to choose size classes for studying cannibalism under seminatural levels of habitat heterogeneity, escape space, and prey abundances. Field experiments were conducted in mesocosms $\left(1.75-\mathrm{m}^{2}\right.$ bottom area plastic cattle watering tanks) located adjacent to the ponds at our study site. Each of the 30 tanks contained $10 \mathrm{~cm}$ of detrital substrate from the ponds, two rocks $\left(\sim 400 \mathrm{~cm}^{2}\right)$, and two $400-\mathrm{cm}^{2}$ clumps of emergent vegetation (Carex aquatilis) to provide the types of refugia that larvae use in the littoral zone of the ponds. The tanks were initially set up in 2001 and by the start of the experiments in 2002 contained a variety of benthic and planktonic invertebrates that were added with the substrate (e.g., worms, midges, epibenthic crustaceans), had colonized as winged adults (beetles, corixid hemipterans), and/or hatched from oviposited eggs (e.g., chironomids midges, mosquitoes, odonates, caddisflies). Pre-experimental samples indicated that invertebrate biomass (total ashfree dry mass [AFDM]), especially that of zooplankton, was slightly lower than that in the source ponds (Wissinger et al. 1999a). Because we wanted cannibal and potential prey hunger levels to be comparable to those in natural populations, we supplemented the prey resource with zooplankton from the ponds (Leptodiaptomus coloradensis, Hesperodiaptomus shoshone, Daphnia middendorfiana, Daphnia rosea-pulex complex) prior to the start of each experiment (June 2002, $0.222 \pm 0.017$ g AFDM; July 2002, $0.210 \pm 0.034$ g AFDM; June 2003, $0.205 \pm 0.029$ g AFDM).

For each experiment, we added five potential victims followed by one potential cannibal that had been held without prey for $24 \mathrm{~h}$. All experiments included nocannibal controls, and the average size of victims and cannibals (given as snout-vent length [SVL]; mean \pm SD) did not differ among treatments (all $P>0.05$ ). In 2002 , we quantified the effects of paedomorphs $(92 \pm 5$ $\mathrm{mm} \mathrm{SVL})$ on age $1+\mathrm{yr}(48 \pm 3 \mathrm{~mm} \mathrm{SVL})$ and age $2+\mathrm{yr}$ $(65 \pm 5 \mathrm{~mm} \mathrm{SVL})$ larvae and, in a second experiment, on two sizes of YOY larvae that corresponded to those encountered in late summer ("small YOY" $=25 \pm 5 \mathrm{~mm}$ SVL) and early autumn ("large YOY" $=37 \pm 4 \mathrm{~mm}$ SVL). During each experiment, we conducted 15-min behavioral trials during which we recorded time spent foraging (see Wissinger et al. [1999b] for a description of foraging behaviors) and activity levels on one individual per tank. We quantified activity by placing a $6 \times 6$ grid (each square $=0.058 \mathrm{~m}^{2}$ ) over the cattle tanks and recorded the number of grids traversed by a randomly chosen focal animal during the 15 -min trials. Time spent foraging and activity levels were highly correlated; thus we present only the latter to avoid redundancy. During the two experiments in 2002, we conducted 28 trials (4 treatments $\times 7$ replicates) on day 6 of the experiment. The rapid disappearance of potential victims precluded additional observations later in the experiments. In
2003, we conducted a third experiment with large larvae (age $\geq 3+\mathrm{yr}=83 \pm 2 \mathrm{~mm} \mathrm{SVL}$ ) as potential cannibals on two sizes of YOY (small $=27 \pm 7 \mathrm{~mm} \mathrm{SVL}$ and large $=$ $37 \pm 3 \mathrm{~mm} \mathrm{SVL})$ and on age $1+$ yr larvae $(49 \pm 3 \mathrm{~mm}$ SVL) using the same protocols as in the experiments with paedomorphs. Behavioral observations of victim activity levels $(6$ treatments $\times 5$ replicates $=30$ trials $)$ were conducted on day 6 as described above in 2002 .

During each experiment, we removed cannibals after 14 d, pumped their stomachs (see Denoël et al. [2006] for a description of methods), and returned each to its source pond. Tanks were drained to ensure a complete count of survivors, which were screened for new injuries (vs. those present at the beginning of the experiment), weighed, and measured (snout-vent length). Because there was no mortality in the controls (i.e., treatment variances $=0$ ), we compared mortality in the presence and absence of cannibals for each combination using Mann-Whitney $U$ tests. Data for nonconsumptive effects met parametric assumptions and were analyzed first with a MANOVA for all responses in the survivors (injuries, activity rates, biomass of gut contents [AFDM], and final body mass), then with ANOVAs for each nonconsumptive response, and finally with Tukey's post hoc test to compare treatment means (Day and Quinn 1989, Scheiner 1993).

\section{Paedomorph density and recruitment}

In July 2003, we conducted a fourth mesocosm experiment to quantify the manner in which paedomorph density affected YOY survival. The experimental protocol was identical to the previous three except that we used 25 YOY per tank and varied the number of potential cannibals $(0,1,2,4,6$, or 8 paedomorphs). These paedomorph and YOY densities correspond to those observed historically in the natural population (Whiteman and Wissinger 2005). The size of victims $(\mathrm{SVL}=26 \pm 5 \mathrm{~mm} ; n=750)$ and cannibals $(96 \pm 7 \mathrm{~mm}$; $n=95$ ) was comparable to that used in "small YOY" treatments in the mesocosm experiments conducted during the previous two summers.

\section{RESULTS}

Microcosm experiments: size constraints on the potential for cannibalism

We observed cannibalism in the microcosms during attacks (victims in the gape of cannibals). The statistics for the survival data in the microcosm experiments are given in Appendix B. In summary, paedomorphs consumed all or nearly all YOY and a few age $1+$ yr larvae in microcosms, but not age $2+$ yr or $3+$ yr larvae. Age $2+$ yr larvae had injuries that suggested attempted cannibalism. These results led us to conduct mesocosm experiments with paedomorphs as potential cannibals and YOY, age $1+\mathrm{yr}$, and $2+\mathrm{yr}$ larvae as potential victims (see Consumptive and nonconsumptive effects... below). Cannibalism by age $3+$ yr larvae in the microcosms occurred mainly on the two smallest size 
classes of YOY, and injuries were found for YOY and age $1+\mathrm{yr}$ survivors (Appendix B). Thus, for the mesocosm experiments, we combined age $3+\mathrm{yr}$ larvae with age $1+\mathrm{yr}$ and two size classes of YOY larvae.

\section{Consumptive and nonconsumptive effects of cannibalism in field mesocosms}

In field mesocosms, survival of YOY larvae was reduced in the presence of large conspecifics for four of the seven size combinations (Fig. 1). Paedomorphs did not consume any age $2+$ yr larvae and only a few age $1+$ $\mathrm{yr}$ larvae, but preyed heavily on both size classes of YOY (Fig. 1A). There was no cannibalism by age $3+$ yr on age 1+yr larvae, but there was cannibalism on both sizes of YOY (Fig. 1B). In addition to consumptive effects of cannibalism, we observed several nonconsumptive effects on survivors. Statistics for all three experiments and the graphical results for the first experiment (paedomorphs with age $1+\mathrm{yr}$ and $2+\mathrm{yr}$ larvae) are summarized in Appendix C. MANOVA indicated that cannibals had a significant overall impact on the four response variables that we measured during (foraging/activity) and at the end of each experiment (survivors with injuries, gut content biomass, final body mass). Subsequent protected ANOVAs and post hoc comparisons revealed that small larvae had more injuries (missing or damaged appendages or body scars) with cannibals than in the control treatments for all treatment combinations, including those in which successful cannibalism rarely or never occurred (i.e., paedomorphs and age $3+$ yr larvae with age $1+$ yr and $2+$ yr larvae; Appendix C, Table 1). For all but the largest potential victims, we also detected significant reduced activity/foraging rates in the presence of cannibals and reduced gut contents at the end of the experiment. These nonconsumptive effects were most evident in small YOY larvae in which activity rates were $\sim 60-80 \%$ lower with than without cannibals (Figs. 2 and 3; Table 1). In those treatments, small YOY hid under rocks or in vegetation or burrowed in the substrate. At the end of the experiment, the presence of cannibals resulted in $\sim 60$ $90 \%$ reductions in the invertebrate biomass in the guts of small YOY larvae and $\sim 30-40 \%$ reductions in body mass. Paedomorph cannibals also reduced activity rates and gut contents of large YOY and age 1+ yr larvae (Table 1). Across all experiments, there was a clear trend from multiple, strong nonconsumptive for the most disparate sizes to weak or no detectable effect for combinations that differed little in size (Table 1).

\section{Ontogenetic shifts in diet}

Stomach contents of potential cannibals and victims were conflated into the following four categories before weighing and ashing to obtain ash-free dry mass (AFDM): (1) large benthic invertebrates (damselflies, dragonflies, beetles, water bugs, and caddisflies), (2) small benthic invertebrates (diptera larvae, mites, and miscellaneous small invertebrates), (3) epibenthic and planktonic microcrustaceans, and (4) terrestrial and adult insects (emerging diptera, caddisflies, moths, and other terrestrial insects) and miscellaneous benthos (worms and clams). MANOVA indicated there was no shift in diet for either potential cannibals or victims across all prey categories (all $P>0.05$ ). We therefore combined the data for each salamander size combination within each experiment to compare the diets of the potential victims and cannibals with one-way MANOVA and subsequent ANOVA. The diets of the paedomorphs and age $3+$ yr larvae were dominated by large invertebrates, whereas the diets of YOY larvae were dominated $(>95 \%)$ by microcrustaceans and chironomid larvae. The ontogenetic shift in diet was most striking when comparing early YOY larvae, whose diets were dominated by microcrustaceans $(70-80 \%$ AFDM), to potential cannibals for which this prey category was a minor component of the diet (10-20\%; see Appendix D). The diets of age $1+\mathrm{yr}$ and $2+\mathrm{yr}$ larvae were intermediate diets that included both small prey items (microcrustaceans and chironomids) and larger taxa. Small benthic prey (mainly chironomid fly larvae) were eaten by all salamander size classes.

\section{Paedomorph density experiment}

The results of the mesocosm experiments clearly established that small YOY larvae were vulnerable to both consumptive and nonconsumptive effects of cannibalism by paedomorphs. Thus, we wanted to describe the relationship between paedomorph abundance and survival of these small YOY larvae. In this experiment, we used a range of paedomorph densities that we had observed during fluctuations in the natural population (Whiteman and Wissinger 2005) and found that YOY survival declined exponentially with increasing paedomorph abundance (Fig. 4). The per capita consumption rate of cannibals was nearly constant across these densities, with an average of $\sim 0.4$ YOY paedomorph ${ }^{-1} \cdot \mathrm{d}^{-1}$.

\section{Discussion}

\section{Measuring ecologically relevant cannibalism size thresholds}

Cannibalism in size-structured populations typically occurs only above a threshold of the proportional difference between the sizes of cannibals and victims. That difference is probably related to constraints on cannibal gape or the ability of victims to flee or escape during capture and handling (Christensen 1996, Mittlebach and Persson 1998, Juanes 2003). Comparative data suggest that species with age-structured populations typically have higher thresholds (e.g., 55\% to $>140 \%$ for piscivorous fishes; Popova 1967, Claesson et al. 2004, Persson et al. 2006) than those in which size structure occurs mainly within generations (e.g., $20-30 \%$ for dragonflies, Wissinger 1992; 40\% for caddisflies, Greig and Wissinger 2010; $<40 \%$ for terrestrial invertebrates, Polis 1981). Although cannibalism within 


\section{A) Paedomorph cannibals}

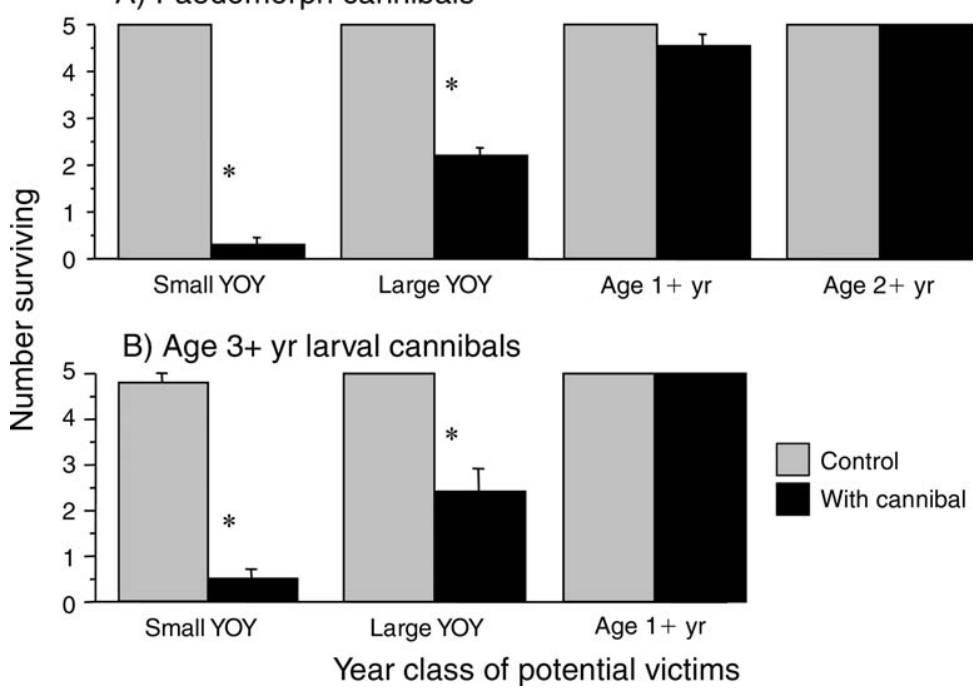

FIG. 1. Survival (mean $+\mathrm{SE}$ ) of tiger salamander (Ambystoma tigrinum nebulosum) larvae with and without (A) paedomorph cannibals and (B) large (age 3+yr) larval cannibals. See Methods for salamander sizes. "YOY" indicates young-of-the-year larvae. Asterisks indicate significant differences $(P<0.05)$ based on Mann-Whitney $U$ tests. The experiments were conducted at the Mexican Cut Nature Preserve in central Colorado, USA.

cohorts of ambystomatid salamanders is commonplace and facilitated by the development of size structure, size thresholds have not been reported (e.g., Polis and Myers 1985, Petranka 1989, Van Buskirk and Smith 1991, Crump 1992, Maret and Collins 1997, Hoffman and Pfennig 1999, Ziemba and Collins 1999, Wildy et al. 2001). In our study, we found that cannibalism between different year classes of tiger salamanders only occurred between individuals that differed by $>50 \%$ in body size (Fig. 5), a threshold that is nearly identical to that found in size-structured populations of stream salamanders (Rudolf 2006). Some size classes that were cannibalized in the microcosms (e.g., age $1+$ yr larvae) were never or rarely cannibalized in the mesocosms (Fig. 5), suggesting that potential victims can avoid detection and/or escape attacks in unconstrained habitats. Although detailed behavioral studies would be needed to quantify the relative importance of avoidance mechanisms, the nonconsumptive data suggest that both might play a role. Reduced activity levels (Figs. 3 and 4) appear to be most important for early YOY larvae, which, in the presence of cannibals, spend most of the time buried motionless in the substrate (see also Walls 1995), making it difficult to locate and observe them during the behavior trials. In contrast, late YOY and age $1+\mathrm{yr}$ larvae spent little time in the substrate and did not reduce activity in the presence of cannibals. However, there were increased injuries, suggesting that escape after attack plays a role in avoiding cannibals for these size classes. For age classes that were never cannibalized,

TABLE 1. Summary of nonconsumptive effects of the threat of tiger salamanders (Ambystoma tigrinum nebulosum) cannibalism in mesocosm experiments with the size combinations shown in Fig. 1.

\begin{tabular}{clccrr}
\hline \hline $\begin{array}{c}\text { Potential } \\
\text { cannibal }\end{array}$ & $\begin{array}{c}\text { Potential } \\
\text { victim }\end{array}$ & $\begin{array}{c}\text { Injuries } \\
\text { (on survivors) }\end{array}$ & Activity & Gut contents & $\begin{array}{c}\text { Growth } \\
\text { in body mass }\end{array}$ \\
\hline Paedomorphs & Small YOY & $+83 \% * * *$ & $-88 \% * * *$ & $-93 \% * * *$ & $-46 \% * * *$ \\
& Large YOY & $+61 \% * * *$ & $-45 \% * * *$ & $-81 \% * * *$ & $-8 \%$ NS \\
& Age 1+ yr & $+63 \% * * *$ & $-47 \% * * *$ & $-28 \% * *$ & $-10 \% \mathrm{NS}$ \\
& Age 2+ yr & $+47 \% * *$ & $-12 \% \mathrm{NS}$ & $-12 \% \mathrm{NS}$ & $-7 \% \mathrm{NS}$ \\
\multirow{5}{*}{ Age 3+ yr } & Small YOY & $+80 \% * * *$ & $-61 \% * * *$ & $-63 \% * * *$ & $-32 \% * * *$ \\
& Large YOY & $+77 \% * *$ & $-22 \% \mathrm{NS}$ & $-12 \% \mathrm{NS}$ & $-2 \% \mathrm{NS}$ \\
& Age 1+ yr & $+26 \% * *$ & $-6 \% \mathrm{NS}$ & $-19 \% \mathrm{NS}$ & $-6 \% \mathrm{NS}$ \\
\hline
\end{tabular}

Notes: Values are calculated as the relative percentage change with vs. without a potential cannibal to standardize the strength of effects across experiments. Asterisks indicate level of significance $(* * P<0.01$; *** $P<0.001)$ based on Tukey's multiple comparisons tests on significant one-way ANOVA results from the original data (see Appendix C). Gut contents were measured as grams of ash-free dry mass. Activity was measured as number of grid moves per 15 minutes. Abbreviations are: NS, not significant; YOY, young-of-the-year larvae. The experiments were conducted at the Mexican Cut Nature Preserve in central Colorado, USA. 


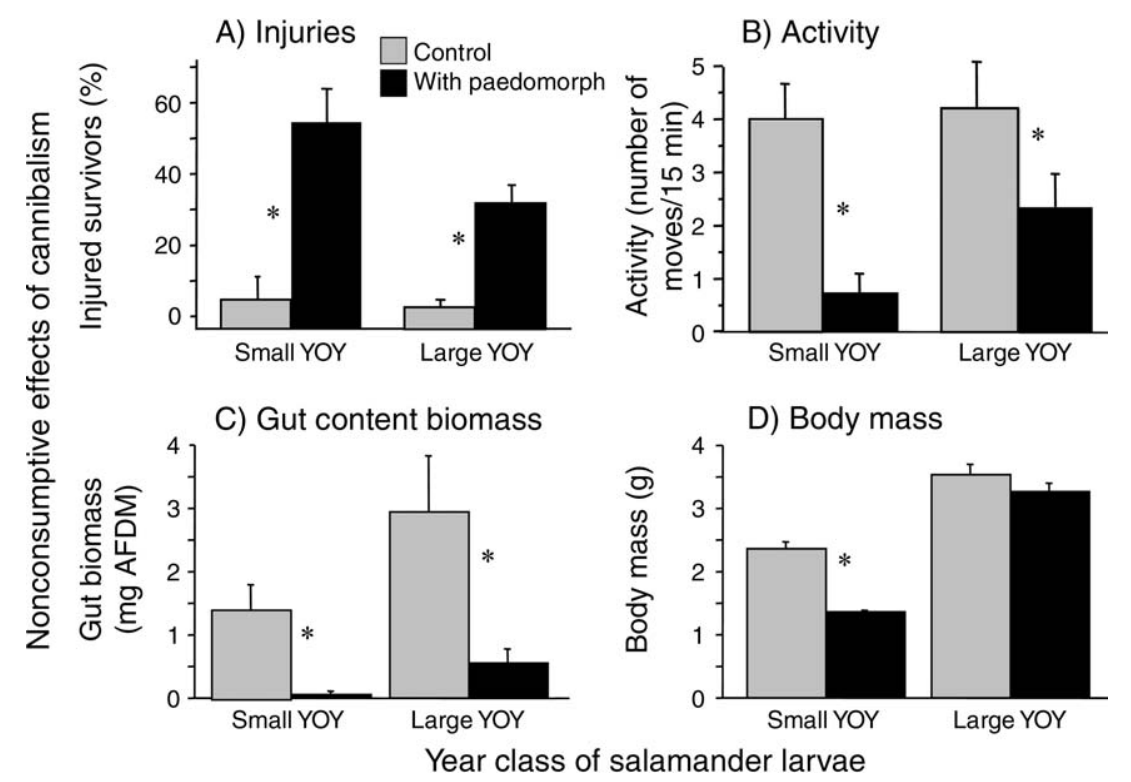

FIG. 2. Nonconsumptive effects (mean $+\mathrm{SE}$ ) of the threat of cannibalism by paedomorphic adult tiger salamanders on two size classes of young-of-the-year (YOY) larvae (see Fig. 1). Asterisks indicate significant differences based on Tukey's post hoc tests after ANOVA (see Appendix C). "AFDM" indicates ash-free dry mass.

injuries provide evidence for asymmetric interference competition (Van Buskirk and Smith 1991, Post et al. 1999, Byström et al. 2003). The results of these microcosm and mesocosm experiments emphasize that inferences about the intensity of cannibalism in natural populations should be based on experiments conducted in spatially heterogeneous habitats with freely interact- ing predators and prey (Persson and Eklöv 1995, Hammond et al. 2007).

When the intensity of cannibalism has been measured for size differences beyond the victim size threshold, two patterns have been observed (Claesson et al. 2004). In many fishes, there are both upper and lower size thresholds, the latter of which is related to low detection

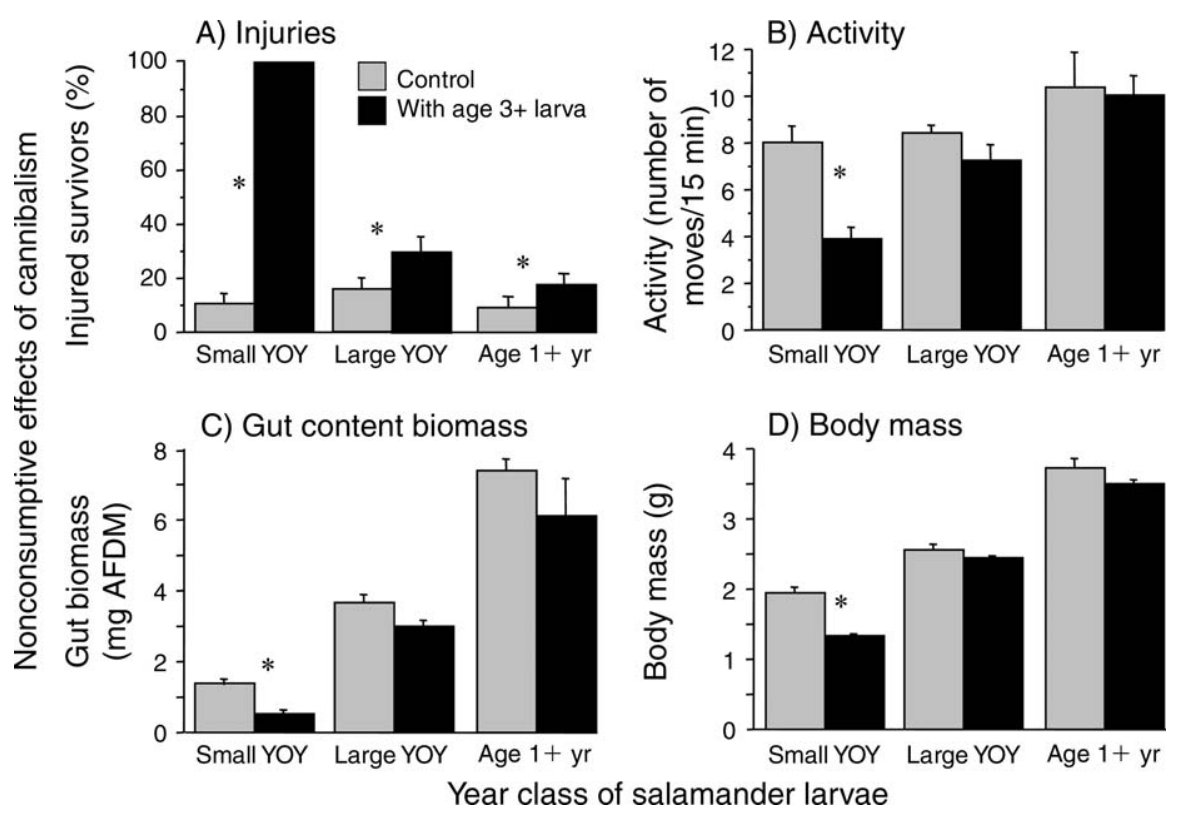

FIG. 3. Nonconsumptive effects (mean $+\mathrm{SE}$ ) of the threat of cannibalism by age $3+\mathrm{yr}$ tiger salamander larvae on age $1+\mathrm{yr}$ larvae and two size classes of young-of-the-year (YOY) larvae (see Fig. 1). Asterisks indicate significant differences based on Tukey's post hoc tests after ANOVA (see Appendix C). "AFDM" indicates ash-free dry mass. 


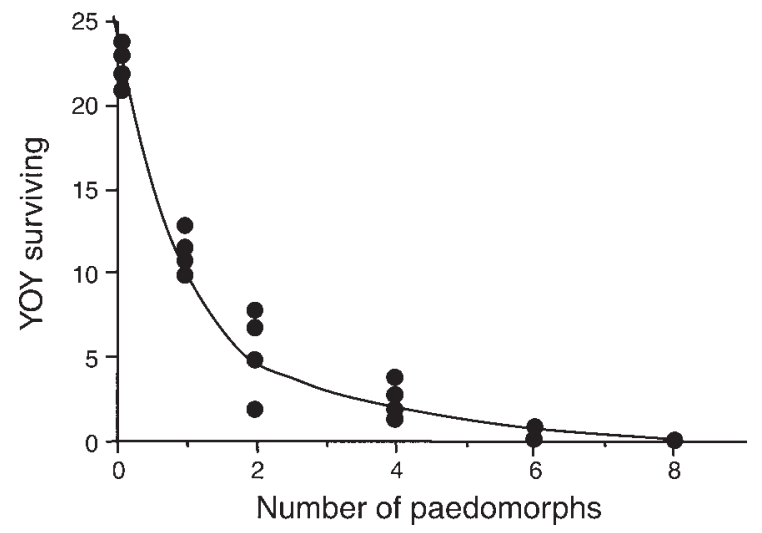

FIG. 4. Survival of young-of-the-year (YOY) tiger salamander larvae across a range of abundances of paedomorphs. Regression statistics for the transformed $(\ln [Y+1])$ dependent variable are $Y=1.254-0.173 \times X ; R^{2}=0.92 ; P<0.0001$.

rates of small conspecifics and/or low retention during handling and ingestion (Lundvall et al. 1999, Juanes 2003). That some cannibals prefer intermediate sizes of conspecifics is consistent with prey profitability models for trade-offs between search/handling time and energy rewards (Stephens and Krebs 1987). In such cases, new cohorts should be initially unaffected by cannibals and can attain sizes that overwhelm the resource base and cause starvation in older size classes, thus creating population dynamics largely driven by competition (Persson et al. 2000, 2004b). In contrast, for many invertebrates and some fishes, there is no lower threshold and cannibalism is most intense on the smallest size classes (Claesson et al. 2004). Our data are consistent with the second pattern; i.e., there is not a second lower victim size threshold in tiger salamanders and cannibalism increases asymptotically to a maximum for YOY victims (Fig. 5). The microcosm data suggest that this pattern is driven mainly by gape-size limitation and that there is a premium on YOY growth rate (see Cannibalism and recruitment failures). When YOY (or eggs) are the most vulnerable size class in cannibalistic species, dominant cohorts can regulate recruitment and drive cannibalism-induced population cycles (Hastings and Constantino 1987, Claessen et al. 2004).

\section{Nonconsumptive effects of cannibals on victims}

The nonconsumptive effects of cannibals on victims that we observed (increased injury and decreased activity, stomach contents, and growth) have been documented in other cannibalistic species (e.g., Van Buskirk 1992, Ziemba and Collins 1999, Biro et al. 2003, Rudolf 2006, 2008) and are a common feature of the interactions between coevolved predators and prey (Lima and Dill 1990, Werner and Peacor 2003, Sih 2004, Peckarsky et al. 2008). The strengths of these effects are highest on YOY salamanders and decrease as victim size increases so that injury is the only nonconsumptive consequence of cannibals on adjacent or next to adjacent age classes (Table 1). This size variation in nonconsumptive effects on victim activity, foraging, and growth is consistent with previous empirical and theoretical studies for predators in general (Abrams and Rowe 1996). That we observed decreased rather than increased YOY activity in the presence of cannibals is perhaps surprising given the evidence for gape limitation. It is precisely in this situation that one might expect the opposite strategy; i.e., increased foraging in order to grow fast and escape the size window of cannibalism (Urban 2007). The growth-predation risk trade-off we observed could be related to the inability of YOY salamanders to grow fast enough during their first summer to escape the size threshold. Although large YOY are slightly less vulnerable than small YOY, consumptive and nonconsumptive effects decrease substantially when larvae reach the size typical for larvae in their second summer (age 1+ yr; Figs. 1-3).

Decreased YOY growth in the presence of cannibals could affect population dynamics by (1) offsetting compensatory growth responses in thinned cohorts (e.g., Persson et al. 2004a, Craig et al. 2006, de Roos et al. 2007, van Kooten et al. 2007), (2) reducing winter survival as a result of low body mass (Jørgensen 1992, Pope and Matthews 2002), (3) increasing body size variation, hence asymmetric competition within cohorts (Ziemba et al. 2000, Peacor et al. 2007), and (4) determining whether larvae mature into metamorphic or paedomorphic adults (Whiteman 1994). Injury could also affect population dynamics by diverting resources for growth to regeneration (Harris 1989) and increasing the incidence of skin disease (e.g., Walls and Jaeger 1987). Short-term nonconsumptive effects (growth and survival) of predators on prey are well studied, but the population-level consequences have rarely been demonstrated (Van Buskirk 1992, Peckarsky et al. 2008). A first step for studying the long-term consequences for salamander population dynamics will be to determine

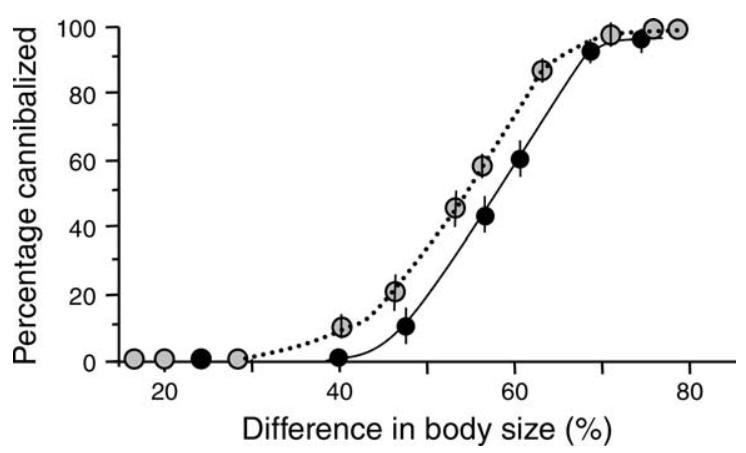

FIG. 5. Summary of the percentage (mean \pm SE) of larval tiger salamanders cannibalized by large conspecifics in microcosms (gray circles and dotted line) and mesocosms (black circles and solid line) vs. the percentage difference in size calculated as [(cannibal SVL - victim SVL)/cannibal SVL] $\times$ 100. "SVL" indicates snout-vent length. 


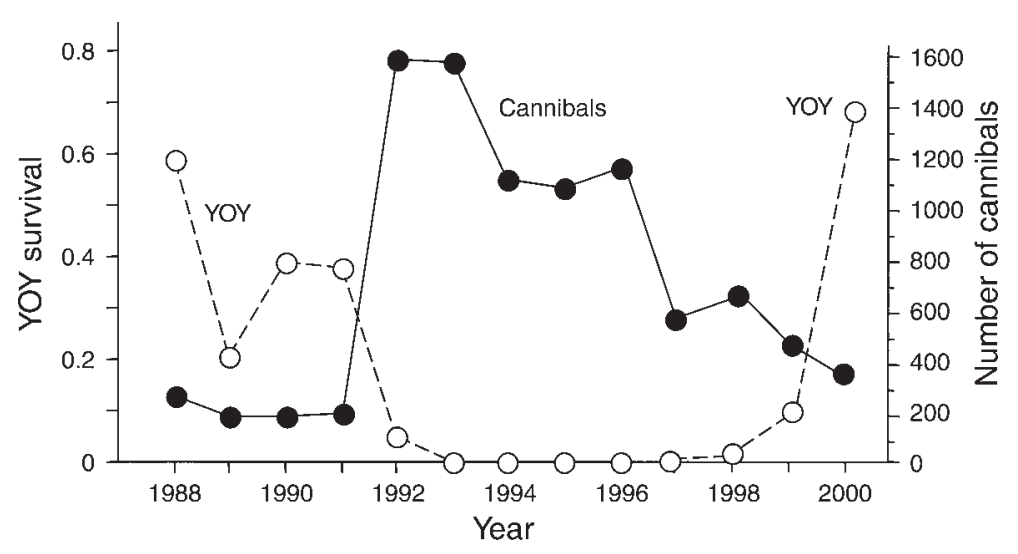

FIG. 6. Relationship between the numbers of potential cannibals inferred from experimental data presented in this paper (i.e., large larvae $[\geq$ age $3+\mathrm{yr}]+$ paedomorphs) and young-of-the-year (YOY) tiger salamander survival in natural populations at the Mexican Cut Nature Preserve, central Colorado, USA. Field data on the number of cannibals and YOY are based on markrecapture censuses from 1988 to 2000 of individually marked (hence known aged) salamanders (Wissinger and Whiteman 1992, Whiteman and Wissinger 2005).

how key indicators (body size, injuries, and disease) vary in late summer between YOY cohorts that develop in years with high vs. low densities of paedomorphs.

\section{Cannibalism and recruitment failures}

Long-term census data at our main study site provide evidence that fluctuations in salamander populations are related to recruitment failures (Wissinger and Whiteman 1992, Whiteman and Wissinger 2005). The fluctuations are characterized by three to four years of strong recruitment followed by six to seven years during which most or all YOY disappear annually before reaching age 1+ yr larvae (Whiteman and Wissinger 2005). The onset of cohort failures occurs when the first of the three to four strong cohorts from the recruitment period reach the size threshold for cannibalism that we experimentally identified in this paper (i.e., age $3+$ yr larvae and paedomorphs). The relationship between the abundance of these cannibalistic size classes and YOY survival is striking (Fig. 6) and similar to the patterns observed in other "dominance-repression" cycles (e.g., Gaines and Roughgarden 1985, Hastings and Constantino 1987, McCauley and Murdoch 1987, Van Buskirk 1992). The results of the paedomorph density experiment (Fig. 4) indicate that the number of large salamanders that are able to cannibalize YOY in dominant cohorts is more than sufficient to eliminate recruitment. In that experiment, we observed a consumption rate of 0.4 YOY paedomorph ${ }^{-1} \cdot \mathrm{d}^{-1}$ (see Fig. 4). The number of large larvae and paedomorphs (600-1400 cannibals; Fig. $6)$ in the population during the years of recruitment failures indicate that they have the potential to consume 14000-33 600 YOY annually $\left(60 \mathrm{~d} \times 0.4 \mathrm{~d}^{-1} \times 600-\right.$ 1400 cannibals), assuming a time window of two months. In contrast, the maximum starting size of cohorts is likely to be only $\sim 4800-8600$ embryos (maximum fecundity per female $\times$ number of females breeding during those years; H. H. Whiteman, unpub- lished data). The actual number of YOY larvae in a given year is likely to be much lower given that (1) we used maximum rather than mean fecundity values, (2) some embryos are eaten by invertebrate predators (Wissinger et al. 1999a), and (3) the window of YOY vulnerability is probably longer than two months. Thus, even if encounter rates in the ponds are lower than those observed in the mesocosms, cannibalism by the large number of paedomorphs observed in dominant cohorts should completely eliminate YOY. Theory suggests population cycles that are driven by recruitment regulation are most likely when YOY are the most vulnerable size class (see Measuring ecologically relevant... above) and when there is little overlap in diet between cannibals and YOY (Claesson et al. 2004, Persson et al. 2004b), as is suggested by the dietary data from our experiments (Appendix D). We cannot eliminate the possibility that dominant cohorts of paedomorphs also affect recruitment through resource depression (de Roos and Persson 2003, Claesson et al. 2004, Persson et al. 2004a). Although dietary data presented here (Appendix D) suggest that is unlikely, paedomorphs have extremely broad diets (Wissinger et al. 1999a), and it is conceivable that individuals in dominant cohorts switch to less preferred small-prey categories after reducing densities of large benthic taxa. Regardless of the potential interplay with intraspecific competition, our results strongly implicate cannibalism as one likely explanation for recruitment patterns in this species.

Understanding the mechanisms that underlie natural fluctuations in population size of amphibians, and thus distinguishing them from amphibian declines related to human activities, requires a combination of long-term data and experimentation (Pechmann and Wilbur 1994, Marsh 2001). Most long-term studies on natural fluctuations have focused on extrinsic factors such as rainfall (Pechmann et al. 1991), shifts in canopy cover 
from terrestrial succession (Skelly et al. 1999), changes in preferred breeding habitats within metapopulations (Petranka et al. 2004), and episodic recruitment associated with climatically favorable and unfavorable years for breeding (reviewed by Marsh 2001). Our results provide evidence that at least for some amphibians, fluctuations can be generated intrinsically and that cannibalism can play an important role in the long-term dynamics of species with age-structured populations.

\section{ACKNowledgments}

We greatly appreciate field assistance from Amy Benson, Jessica Boynton, Erin Olson, Jackie Doyle, Hamish Greig, Rich Schultheis, Sara Mattie, Dhira Dale, Katrina Butkas, Mark Galatowitsch, and Mike O'Brien. Comments by Bobbi Peckarsky and two anonymous reviewers greatly improved earlier versions of the manuscript. M. Denoël was a Research Associate at the Fonds de la Recherche Scientifique (FNRS) and was funded by the Fulbright Foundation and FNRS grants 1.5.011.03, 1.5.120.04, F.4718.07, 1.5.199.07, and 1.5.013.08. H. H. Whiteman was funded by the Center for Institutional Studies and Research at Murray State University and the National Science Foundation (DEB-0109436). S. A. Wissinger was funded by the National Science Foundation (DEB-0108931).

\section{Literature Cited}

Abrams, P. A. 2007. Defining and measuring the impacts of dynamic traits on interspecific interactions. Ecology 88:25552562.

Abrams, P. A., and L. Rowe. 1996. The effects of predation on the age and size of maturity of prey. Evolution 50:1052-1061.

Alford, R. A., P. M. Dixon, and J. H. K. Pechmann. 2001. Global amphibian population declines. Nature 414:449-500.

Andersson, J., P. Byström, D. Claessen, L. Persson, and A. M. De Roos. 2007. Stabilization of population fluctuations due to cannibalism promotes resource polymorphism in fish. American Naturalist 169:820-829.

Benoît, H. P., E. McCauley, and J. R. Post. 1998. Testing the demographic consequences of cannibalism in Tribolium confusum. Ecology 79:2839-2851.

Biro, P. A., J. R. Post, and E. A. Parkinson. 2003. From individual to populations: Prey fish risk-taking mediates mortality in whole-system experiments. Ecology 84:24192431.

Byström, P., J. Andersson, L. Persson, and A. de Roos. 2003. Size-dependent resource limitation and foraging-predation risk trade-offs: growth and habitat use in Arctic char. Oikos 104:109-121.

Christensen, B. 1996. Predator foraging capabilities and prey antipredator behaviors: pre- versus post-capture constraints on size-dependent predator-prey interactions. Oikos 76:368-380.

Claessen, D., and A. M. de Roos. 2003. Bistability in a sizestructured population model of cannibalistic fish: a continuation study. Theoretical Population Biology 64:49-65.

Claessen, D., A. M. de Roos, and L. Persson. 2004. Population dynamic theory of size-dependent cannibalism. Proceedings of the Royal Society B 271:333-340.

Claus-Walker, D. B., P. H. Crowley, and F. Johansson. 1997. Fish predation, cannibalism, and larval development in the dragonfly Epitheca cynosura. Canadian Journal of Zoology 75:687-696.

Collins, J. P. 1981. Distribution, habitats, and life history variation in the tiger salamander, Ambystoma tigrinum, in east-central and southeast Arizona. Copeia 1981:666-675.

Collins, J. P., and A. Storfer. 2003. Global amphibian declines: sorting the hypotheses. Diversity and Distribution 3:89-98.
Craig, J. K., B. J. Burke, L. B. Crowder, and J. A. Rice. 2006. Prey growth and size-dependent predation in juvenile estuarine fishes: experiment and model analyses. Ecology 87:2366-2377.

Crump, M. L. 1992. Cannibalism in amphibians. Pages 256276 in M. A. Elgar and B. J. Crespi, editors. Cannibalism: ecology and evolution in diverse taxa. Oxford University Press, Oxford, UK.

Day, R. W., and G. P. Quinn. 1989. Comparisons of treatments after an analysis of variance in ecology. Ecological Monographs 59:433-463.

Denoël, M., H. H. Whiteman, and S. A. Wissinger. 2006. Temporal shift of diet in alternative cannibalistic morphs of the tiger salamander. Biological Journal of the Linnean Society 89:373-382.

de Roos, A. M., and L. Persson. 2003. Competition in sizestructured populations: mechanisms inducing cohort formation and population cycles. Theoretical Population Biology 63:1-16.

de Roos, A. M., T. Schellekens, T. van Kooten, K. van de Wolfshaar, D. Claessen, and L. Persson. 2007. Food dependent growth leads to overcompensation in stagespecific biomass when mortality increases: the influence of maturation versus reproduction regulation. American Naturalist 170:E59-E76.

Diekmann, O., R. M. Nisbet, W. C. S. Gurney, and F. Van den Bosch. 1986. Simple mathematical models for cannibalism: a critique and a new approach. Mathematical Biosciences 78: 21-46.

Donovan, N. S., R. A. Stein, and M. M. White. 1997. Enhancing percid stocking success by understanding age-0 piscivore-prey interactions in reservoirs. Ecological Applications 7:1311-1329.

Elgar, M. A., and B. J. Crespi, editors. 1992. Cannibalism: ecology and evolution among diverse taxa. Oxford University Press, Oxford, UK.

Fox, L. R. 1975. Cannibalism in natural populations. Annual Review of Ecology and Systematics 6:87-106.

Gaines, S., and J. Roughgarden. 1985. Larval settlement rate: a leading determinant of structure in an ecological community of the intertidal zone. Proceedings of the National Academy of Sciences (USA) 82:3707-3711.

Greig, H. S., and S. A. Wissinger. 2010. Reinforcing abiotic and biotic time constraints facilitate the broad distribution of a generalist with fixed traits. Ecology 91, in press.

Hammond, J. I., B. T. Luttbeg, and A. Sih. 2007. Predator and prey space use: dragonflies and tadpoles in an interactive game. Ecology 88:1525-1535.

Harris, R. N. 1989. Non-lethal injuries to organisms as a method of population regulation. American Naturalist 134: $835-847$.

Hastings, A., and R. F. Constantino. 1987. Cannibalistic egglarva interactions in Tribolium: an explanation for the oscillations in population numbers. American Naturalist 120:36-52.

Hastings, A., and R. F. Constantino. 1991. Oscillations in population numbers: age-dependent cannibalism. Journal of Animal Ecology 60:471-482.

Hoffman, E. A., and D. W. Pfennig. 1999. Proximate causes of polyphenism in larval tiger salamanders. Ecology 80:10761080.

Houlahan, J. E., C. S. Findlay, B. R. Schmidt, A. H. Meyer, and S. L. Kuzmin. 2000. Quantitative evidence for amphibian population declines. Nature 404:752-755.

Jørgensen, C. B. 1992. Growth and reproduction. Pages 439466 in M. E. Feder and W. W. Burggren, editors. Environmental physiology of the amphibians. University of Chicago Press, Chicago, Illinois, USA.

Juanes, F. 2003. The allometry of cannibalism in piscivorous fishes. Canadian Journal of Fisheries and Aquatic Sciences 60:594-602. 
Kiesecker, J. M., A. R. Blaustein, and L. K. Belden. 2001. Complex causes of amphibian population declines. Nature 410:681-683.

Lima, S. C., and L. M. Dill. 1990. Behavioral decisions made under the risk of predation: a review and prospectus. Canadian Journal of Zoology 268:619-640.

Lundvall, D., R. Svänback, L. Persson, and P. Byström. 1999. Size-dependent predation in piscivores: interactions between predator foraging and prey avoidance abilities. Canadian Journal of Fisheries and Aquatic Sciences 56:1285-1292.

Maret, T. J., and J. P. Collins. 1997. Ecological origin of morphological diversity: a study of alternative trophic phenotypes in larval salamanders. Evolution 51:898-905.

Marsh, D. M. 2001. Fluctuations in amphibian populations: a meta-analysis. Biological Conservation 101:327-335.

McCauley, E. F., and W. W. Murdoch. 1987. Cyclic and stable populations: plankton as paradigm. American Naturalist 129:97-121.

Mertz, D. B. 1972. The Tribolium model and the mathematics of population growth. Annual Review of Ecology and Systematics 3:51-78.

Mittlebach, G. G., and L. Persson. 1998. The ontogeny of piscivory and its consequences. Canadian Journal of Fisheries and Aquatic Sciences 55:1454-1465.

Park, T., D. B. Mertz, W. Grodzinski, and T. Prus. 1965. Cannibalistic predation in populations of flour beetles. Physiological Zoology 38:289-321.

Peacor, S. D., L. Schiesari, and E. E. Werner. 2007. Mechanisms of nonlethal predator effect on cohort size variation: ecological and evolutionary implications. Ecology 88:1536-1547.

Pechmann, J. H., D. E. Scott, R. D. Semlitsch, J. P. Caldwell, L. J. Vitt, and J. W. Gibbons. 1991. Declining amphibian populations: the problem of separating human impact from natural fluctuations. Science 253:892-895.

Pechmann, J. H., and H. M. Wilbur. 1994. Putting declining amphibians populations in perspective: natural fluctuations and human impacts. Herpetologica 50:65-84.

Peckarsky, B. L., P. A. Abrams, D. I. Bonick, L. M. Dill, J. H. Grabowski, B. Luttbeg, J. L. Orrock, S. D. Peacor, E. L. Preisser, O. J. Schmitz, and G. C. Trussell. 2008. Revisiting the classics: considering non-consumptive effects in textbook examples of predator-prey interactions. Ecology 89:24162425.

Persson, L., A. Bertolo, and A. M. De Roos. 2006. Temporal stability in size distributions and growth rates of three Esox lucius populations: A result of cannibalism? Journal of Fish Biology 69:461-472.

Persson, L., P. Byström, and E. Wahlström. 2000. Cannibalism and competition in Eurasian perch: population dynamics of an ontogenetic omnivore. Ecology 81:1058-1071.

Persson, L., D. Claessen, A. M. de Roos, P. Byström, S. Sjögren, R. Svanbäck, and E. Westman. 2004a. Cannibalism in a size-structured population: energy extraction and control. Ecological Monographs 74:135-157.

Persson, L., A. M. de Roos, and A. Bertolo. 2004b. Predicting shifts in dynamics of cannibalistic field populations using individual-based models. Proceedings of the Royal Society 271:2489-2493.

Persson, L., and P. Eklöv. 1995. Prey refuges affecting interactions between piscivorous perch and juvenile perch and roach. Ecology 76:70-81.

Petranka, J. W. 1989. Density-dependent growth and survival of larval Ambystoma: evidence from whole-pond manipulations. Ecology 70:1752-1767.

Petranka, J. W., C. K. Smith, and A. F. Scott. 2004. Identifying the minimal demographic unit for monitoring pond-breeding amphibians. Ecological Applications 14:1065-1078.

Polis, G. A. 1980. The effect of cannibalism on the demography and activity of a natural population of desert scorpion. Behavioral Ecology and Sociobiology 7:25-35.
Polis, G. A. 1981. The evolution and dynamics of intraspecific predation. Annual Review of Ecology and Systematics 12: 225-251.

Polis, G. A., and C. A. Myers. 1985. A survey of intraspecific predation among reptiles and amphibians. Journal of Herpetology 19:99-107.

Pope, K. L., and K. R. Matthews. 2002. Influence of anuran prey on the condition and distribution of Rana muscosa in the Sierra Nevada. Herpetologica 58:787-793.

Popova, O. 1967. The 'predator-prey' relationship among fishes. Pages 359-376 in S. Gerking, editor. The biological basis of freshwater fish production. Oxford University Press, Oxford, UK.

Post, D. M. 2003. Individual variation in the timing of ontogenetic niche shifts in largemouth bass. Ecology 84: $1298-1310$

Post, J. R., E. A. Parkinson, and N. T. Johnston. 1999. Densitydependent processes in structured fish populations: interaction strengths in whole-lake experiments. Ecological Monographs 69:155-175.

Rudolf, V. H. W. 2006. The influence of size-specific indirect interactions in predator-prey systems. Ecology 87:362-271.

Rudolf, V. H. W. 2007a. Consequences of stage-structured predators: cannibalism, behavioral effects, and trophic cascades. Ecology 88:2991-3003.

Rudolf, V. H. W. 2007b. The interaction of cannibalism and omnivory: consequences for community dynamics. Ecology 88:2697-2705.

Rudolf, V. H. W. 2008. Impact of cannibalism on predatorprey dynamics: size-structured interactions and apparent mutualism. Ecology 89:1650-1660.

Scheiner, S. M. 1993. MANOVA: multiple response variables and multispecies interactions. Pages 94-112 in S. M. Scheiner and J. Gurevitch, editors. Design and analysis of ecological experiments. Chapman and Hall, New York, New York, USA.

Sexton, O. J., and J. R. Bizer. 1978. Life history patterns of Ambystoma tigrinum in montane Colorado. American Midland Naturalist 99:101-118.

Sih, A. 1982. Foraging strategies and the avoidance of predation by an aquatic insect, Notonecta hoffmanni. Ecology 63:786-796.

Sih, A. 2004. Predation risk and the evolutionary ecology of reproductive behavior. Journal of Fish Biology 45A:111-130.

Skelly, D. K., E. E. Werner, and S. A. Cortwright. 1999. Longterm distributional dynamics of a Michigan amphibian assemblage. Ecology 80:2326-2337.

Skelly, D. K., K. L. Yurewicz, E. E. Werner, and R. A. Relyea. 2003. Estimating decline and distributional change in amphibians. Conservation Biology 17:744-751.

Sprules, W. G. 1974. The adaptive significance of paedogenesis in North American species of Ambystoma (Amphibia: Caudata): an hypothesis. Canadian Journal of Zoology 52: 393-400.

Stephens, D. W., and J. R. Krebs. 1987. Foraging theory. Princeton University Press, Princeton, New Jersey, USA.

Urban, M. C. 2007. The growth-predation risk trade-off under a growing gape-limited predation threat. Ecology 88:25872597.

Van Buskirk, J. 1992. Competition, cannibalism, and size class dominance in a dragonfly. Ecology 65:455-464.

Van Buskirk, J., and D. C. Smith. 1991. Density-dependent population regulation in a salamander. Ecology 72:17471756.

Van Kooten, T., L. Persson, and A. M. de Roos. 2007. Sizedependent mortality induces life-history changes mediated through population dynamical feedbacks. American Naturalist 170:258-270.

Walls, S. C. 1995. Differential vulnerability to predation and refuge use in competing larval salamanders. Oecologia 101: 86-93. 
Walls, S. C., and R. G. Jaeger. 1987 Aggression and exploitation as mechanisms of competition in larval salamanders. Canadian Journal of Zoology 65:2938-2944.

Werner, E. E., and S. D. Peacor. 2003. A review of traitmediated indirect interactions in ecological communities. Ecology 84:1083-1100.

Whiteman, H. H. 1994. Evolution of facultative paedomorphosis in salamanders. Quarterly Review of Biology 69:205221.

Whiteman, H. H., J. P. Sheen, E. Johnson, A. VanDeusen, R. T. Cargille, and T. Sacco. 2003. Heterospecific prey and trophic polyphenism in larval tiger salamanders. Copeia 2003:56-67.

Whiteman, H. H., and S. A. Wissinger. 2005. Amphibian population cycles and long-term data. Pages 177-184 in M. Lanoo, editor. Amphibian declines: conservation status of U.S. species. California University Press, Berkeley, California, USA.

Wildy, E. L., D. P. Chivers, J. M. Kiesecker, and A. R. Blaustein. 2001. The effects of food level and conspecific density on biting and cannibalism in larval long-toed salamanders, Ambystoma macrodactylum. Oecologia 128: 202-209.

Wissinger, S. A. 1992. Niche overlap and the potential for competition and intraguild predation in size-structured populations. Ecology 73:1431-1444.

Wissinger, S. A., A. J. Bohonak, H. H. Whiteman, and W. S. Brown. 1999a. Subalpine wetlands in Colorado: habitat permanence, salamander predation and invertebrate communities. Pages 757-790 in D. P. Bazter and S. A. Wissinger, editors. Invertebrates in freshwater wetlands of North America: ecology and management. John Wiley and Sons, New York, New York, USA.

Wissinger, S. A., and H. H. Whiteman. 1992. Fluctuation in a Rocky Mountain population of salamanders: Anthropogenic acidification or natural variation? Journal of Herpetology 26: 377-391.

Wissinger, S. A., H. H. Whiteman, G. B. Sparks, G. L. Rouse, and W. S. Brown. 1999b. Foraging trade-offs along a predator-permanence gradient in subalpine wetlands. Ecology 80:2102-2116.

Woodward, G., and A. G. Hildrew. 2002. Body-size determinants of niche overlap and intraguild predation within a complex food web. Journal of Animal Ecology 71:1063-1074.

Woodward, G., D. C. Speirs, and A. G. Hildrew. 2005. Quantification and temporal resolution of a complex sizestructured food web. Advances in Ecological Research 36:85135.

Ziemba, R. E., and J. P. Collins. 1999. Development of size structure in tiger salamanders: the role of intraspecific interference. Oecologia 130:534-529.

Ziemba, R. E., M. T. Myers, and J. P. Collins. 2000. Foraging under the risk of cannibalism leads to divergence in body size among tiger salamanders. Oecologia 124:225-231.

\section{APPENDIX A}

Photographs of the study site and of paedomorphic adult and young-of-the-year tiger salamanders (Ecological Archives E091039-A1).

\section{APPENDIX B}

Results of short-term microcosm experiments to determine the manner in which size affects the potential for inter-cohort cannibalism in tiger salamanders (Ecological Archives E091-039-A2).

\section{APPENDIX C}

Statistical analyses of four nonconsumptive responses to the threat of cannibalism by tiger salamanders in mesocosm experiments (Ecological Archives E091-039-A3).

\section{APPENDIX D}

Comparative dietary data of salamander cannibals and victims in mesocosms (Ecological Archives E091-039-A4). 
Scott A. Wissinger, Howard H. Whiteman, Mathieu Denoël, Miranda L. Mumford, and Catherine B. Aubee. 2010. Consumptive and nonconsumptive effects of cannibalism in fluctuating age-structured populations. Ecology 91:549-559.

Appendix A. Photographs of the study site and of paedomorphic adult and young-of-the-year tiger salamanders.

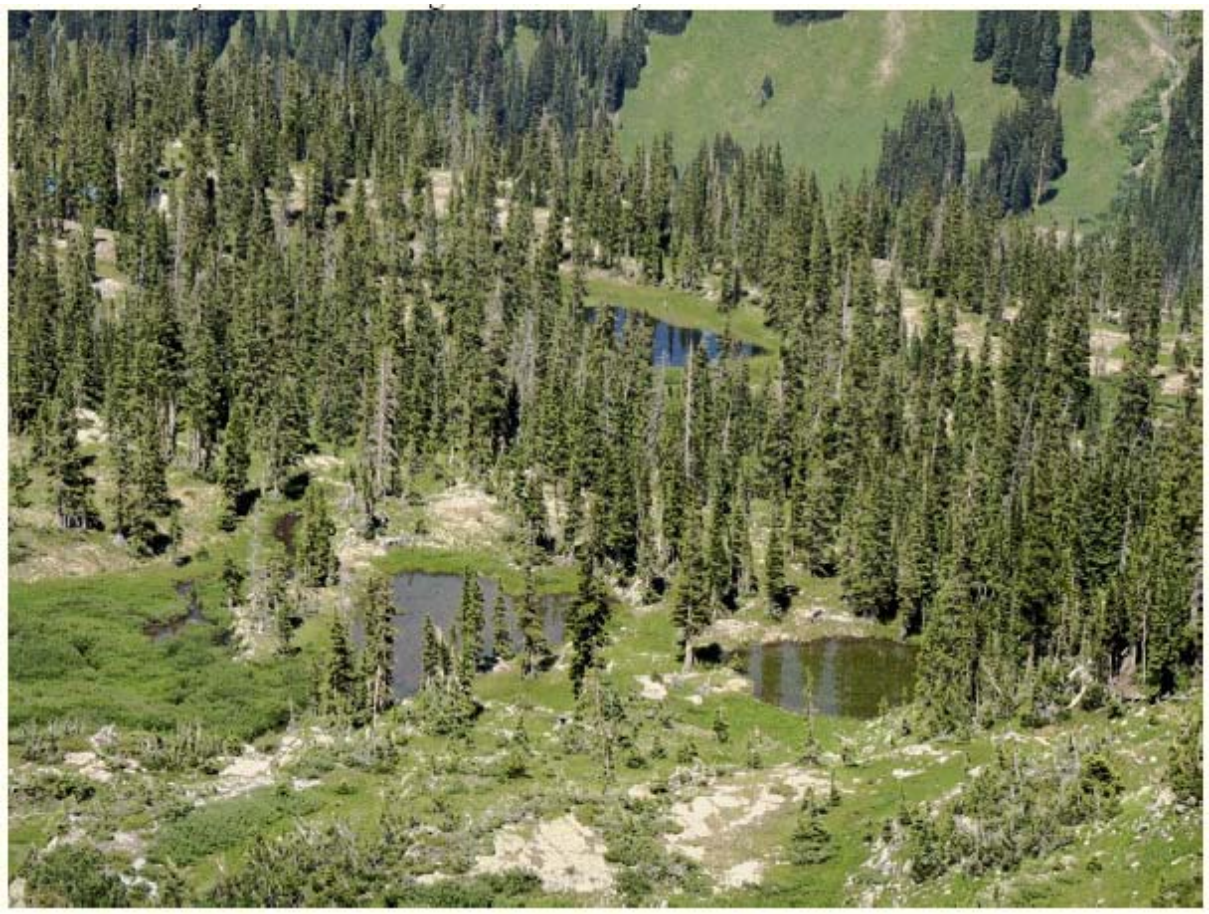

Aerial view of several of the ponds at The Nature Conservancy's Mexican Cut Nature Preserve near the Rocky Mountain Biological Laboratory in the Elk Mountains of Colorado, USA.

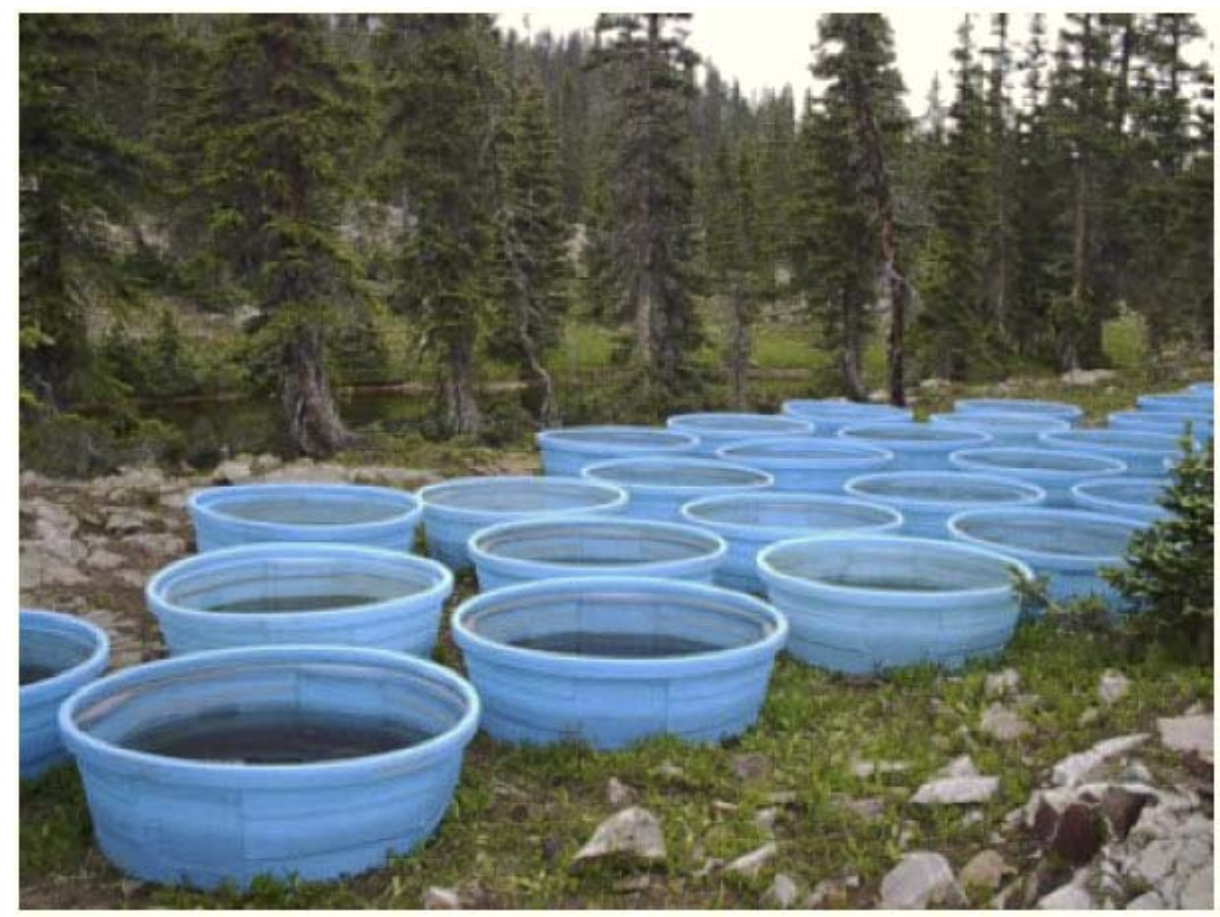

Experimental mesocosms at the Mexican Cut Nature Preserve. Location of mesocosms is visible in the upper left hand corner of the aerial view of the natural ponds above. 


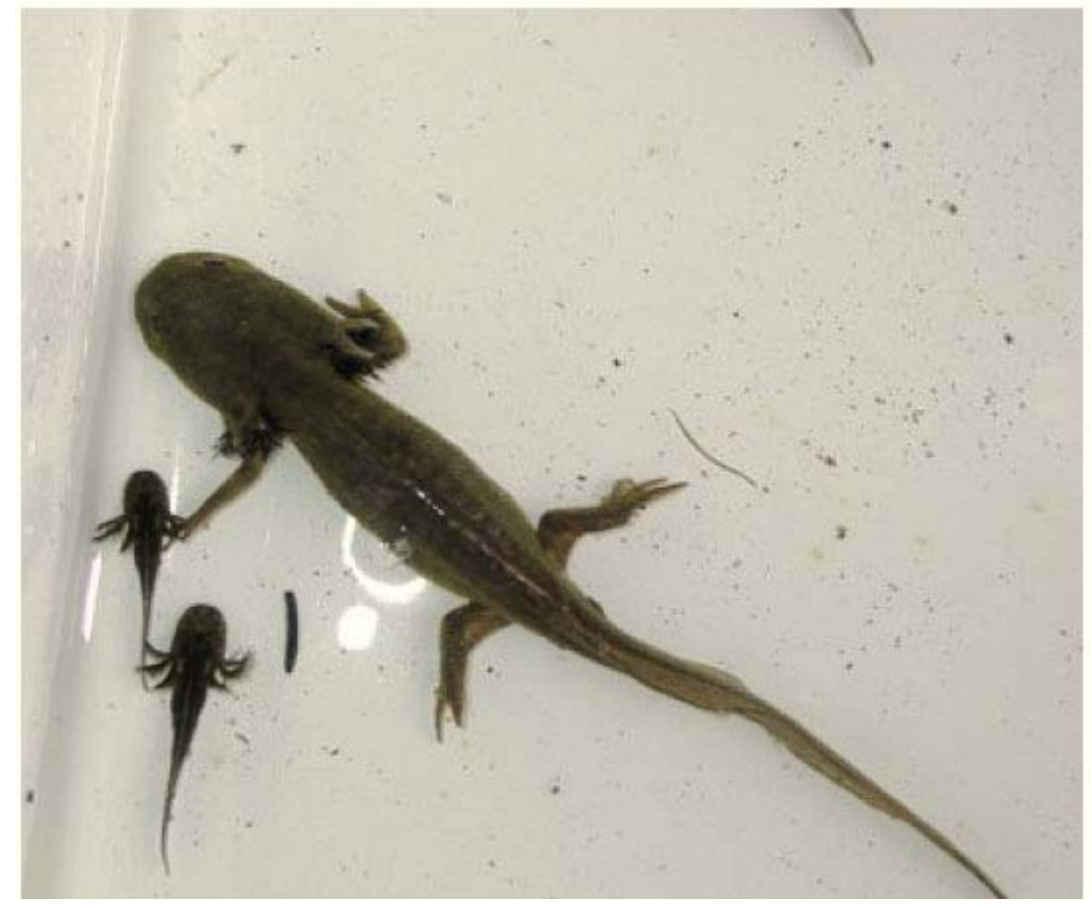

Paedomorphic adult and young-of-the-year larval tiger salamanders (Ambystoma tigrinum nebulosum). 


\section{Ecological Archives E091-039-A2}

Scott A. Wissinger, Howard H. Whiteman, Mathieu Denoël, Miranda L. Mumford, and Catherine B. Aubee. 2010.

Consumptive and nonconsumptive effects of cannibalism in fluctuating age-structured populations. Ecology 91:549-559.

Appendix B (Table B1). Results of short-term (72 h) microcosm experiments to determine how size affects the potential for inter-cohort cannibalism in tiger salamanders.

\begin{tabular}{|c|c|c|c|c|c|c|c|c|}
\hline \multirow[t]{2}{*}{ Date } & \multicolumn{2}{|c|}{ Potential cannibal } & \multicolumn{2}{|c|}{ Potential victims } & \multicolumn{2}{|c|}{$\begin{array}{l}\text { Mann-Whitney U } \\
\text { Prey Survival }\end{array}$} & \multirow[t]{2}{*}{$\begin{array}{l}\% \text { Survival } \\
\text { w/ cannibals }\end{array}$} & \multirow[t]{2}{*}{$\begin{array}{c}\text { Survivors w/ } \\
\text { injuries? }\end{array}$} \\
\hline & Stage & $\begin{array}{l}\mathrm{SVL} \pm \mathrm{SD} \\
\mathrm{am})(n=5)\end{array}$ & Stage & $\begin{array}{l}\mathrm{SVL} \pm \mathrm{SD} \\
(\mathrm{mm})(n=10)\end{array}$ & $\mathrm{U}$ & $P$ value & & \\
\hline June 2002 & Paedomorphs & $90 \pm 0.5$ & age $3^{+}$yr larvae & $81 \pm 2.7$ & 12.5 & 0.99 & $100 \%$ & no \\
\hline June 2002 & Paedomorphs & $90 \pm 1.0$ & age $2^{+}$yr larvae & $65 \pm 1.5$ & 12.5 & 0.99 & $100 \%$ & no \\
\hline June 2002 & Paedomorphs & $89 \pm 0.3$ & age $1^{+}$yr larvae & $48 \pm 1.3$ & 7.5 & 0.30 & $80 \%$ & yes \\
\hline July 2002 & Paedomorphs & $90 \pm 0.8$ & large YOY & $38 \pm 1.6$ & 0.0 & $<0.01$ & $40 \%$ & yes \\
\hline July 2002 & Paedomorphs & $91 \pm 0.4$ & medium YOY & $28 \pm 2.5$ & 0.0 & $<0.01$ & $10 \%$ & yes \\
\hline July 2002 & Paedomorphs & $91 \pm 0.5$ & small YOY & $19 \pm 2.3$ & 0.0 & $<0.01$ & $0 \%$ & --- \\
\hline June 2003 & $3^{+}$yr larvae & $81 \pm 0.5$ & age $2^{+}$yr larvae & $65 \pm 1.8$ & 12.5 & 0.99 & $100 \%$ & no \\
\hline June 2003 & $3^{+}$yr larvae & $81 \pm 0.6$ & age $1^{+}$yr larvae & $48 \pm 3.0$ & 10.0 & 0.31 & $90 \%$ & yes \\
\hline July 2003 & $3^{+}$yr larvae & $80 \pm 0.2$ & large YOY & $38 \pm 3.0$ & 2.5 & 0.02 & $60 \%$ & yes \\
\hline July 2003 & $3^{+}$yr larvae & $80 \pm 0.3$ & medium YOY & $28 \pm 3.4$ & 0.0 & $<0.01$ & $20 \%$ & yes \\
\hline July 2003 & $3^{+}$yr larvae & $80 \pm 0.6$ & small YOY & $19 \pm 2.1$ & 0.0 & $<0.01$ & $0 \%$ & $-\cdots$ \\
\hline
\end{tabular}

Notes: SVL = snout-vent length; SD = standard deviation. We conducted five replicates of each treatment combination and no-predator controls with two potential victims and one potential cannibal per microcosm. Mann-Whitney U tests compare survival with and without presence of potential cannibals. "----" indicates no survivors. 
Scott A. Wissinger, Howard H. Whiteman, Mathieu Denoël, Miranda L. Mumford, and Catherine B. Aubee. 2010. Consumptive and nonconsumptive effects of cannibalism in fluctuating age-structured populations. Ecology 91:549-559.

Appendix C. Statistical analyses of four nonconsumptive responses to the threat of cannibalism measured on small conspecifics during (activity rates) and at the end (injuries, gut fullness, final mass) of three mesocosm field experiments. The data were first analyzed using a two-way MANOVA for the effects of cannibal presence and size of victims on these response variables. Protected ANOVAs (sensu Scheiner 1993) for each response variable and graphical results are given below. $\mathrm{df}=$ degrees of freedom for numerator, denominator of MANOVAs.

\section{MANOVA statistics}

Experiment $\quad$ Wilks' $\lambda \quad F$ value $\quad P$ value

1) Cannibalism by paedomorphs on age $1^{+}$and $2^{+}$yr larvae $(d f 4,21)$

$\begin{array}{lccc}\text { Presence of cannibal } & 0.016 & 355.6 & <0.0001 * \\ \text { Prey size class } & 0.504 & 5.2 & 0.005^{*} \\ \text { Cannibals } \times \text { prey size } & 0.562 & 4.1 & 0.013^{*}\end{array}$

2) Cannibalism by paedomorphs on two sizes of young-of-the-year (YOY) larvae (df 4, 13)

$\begin{array}{lccc}\text { Presence of Cannibal } & 0.177 & 15.1 & <0.0001 * \\ \text { Prey size class } & 0.120 & 23.8 & <0.0001 * \\ \text { Cannibal } \times \text { prey size } & 0.646 & 1.7 & 0.19\end{array}$

3) Cannibalism by $3^{+}$yr larvae on three size classes of larvae $(8,36)$

$\begin{array}{lccc}\text { Presence of Cannibal } & 0.159 & 23.8 & <0.0001 * \\ \text { Prey size class } & 0.024 & 24.7 & <0.0001 * \\ \text { Cannibal } \times \text { prey size } & 0.252 & 4.8 & 0.008 *\end{array}$


ANOVA statistics for each response variable in each of the experiments, and graphical results for Experiment 1

Experiment 1) Nonconsumptive effects of paedomorphs on age $1^{+}$and $2^{+}$yr larvae

\begin{tabular}{lcccc} 
a) $\%$ injured & df & mss & $F$ value & $P$ value \\
presence of cannibal & 1 & 1008.0 & 7.83 & $0.01 *$ \\
prey size class & 1 & 82.3 & 0.68 & 0.43 \\
cannibal $\times$ size class & 1 & 82.2 & 0.68 & 0.43 \\
error & 24 & 129.1 & & \\
\hline
\end{tabular}

\begin{tabular}{|c|c|c|c|c|}
\hline b) activity rates & df & mss & $F$ value & $P$ value \\
\hline presence of cannibal & 1 & 51.5 & 13.3 & $0.001 *$ \\
\hline prey size class & 1 & 5.4 & 1.3 & 0.26 \\
\hline cannibal $\times$ size class & 24 & 24.1 & 6.3 & 0.02 \\
\hline
\end{tabular}

error

c) gut fullness $\quad$ df mss $F$ value $P$ value

$\begin{array}{lllll}\text { presence of cannibal } & 1 & 161.6 & 6.0 & 0.02 *\end{array}$

$\begin{array}{lllll}\text { prey size class } & 1 & 386.9 & 14.2 & 0.001 *\end{array}$

$\begin{array}{lllll}\text { cannibal } \times \text { size class } & 1 & 8.6 & 0.3 & 0.32\end{array}$

$\begin{array}{lll}\text { error } & 24 & 3.9\end{array}$

$\begin{array}{lcccc}\text { d) final larval mass } & \text { df } & \text { mss } & F \text { value } & P \text { value } \\ \text { presence of cannibal } & 1 & 0.1 & 0.54 & 0.47 \\ \text { prey size class } & 1 & 196.6 & 1151.8 & <0.0001 * \\ \text { cannibal } \times \text { size class } & 1 & 1.7 & 10.3 & 0.003 \\ \text { error } & 24 & 0.17 & & \end{array}$



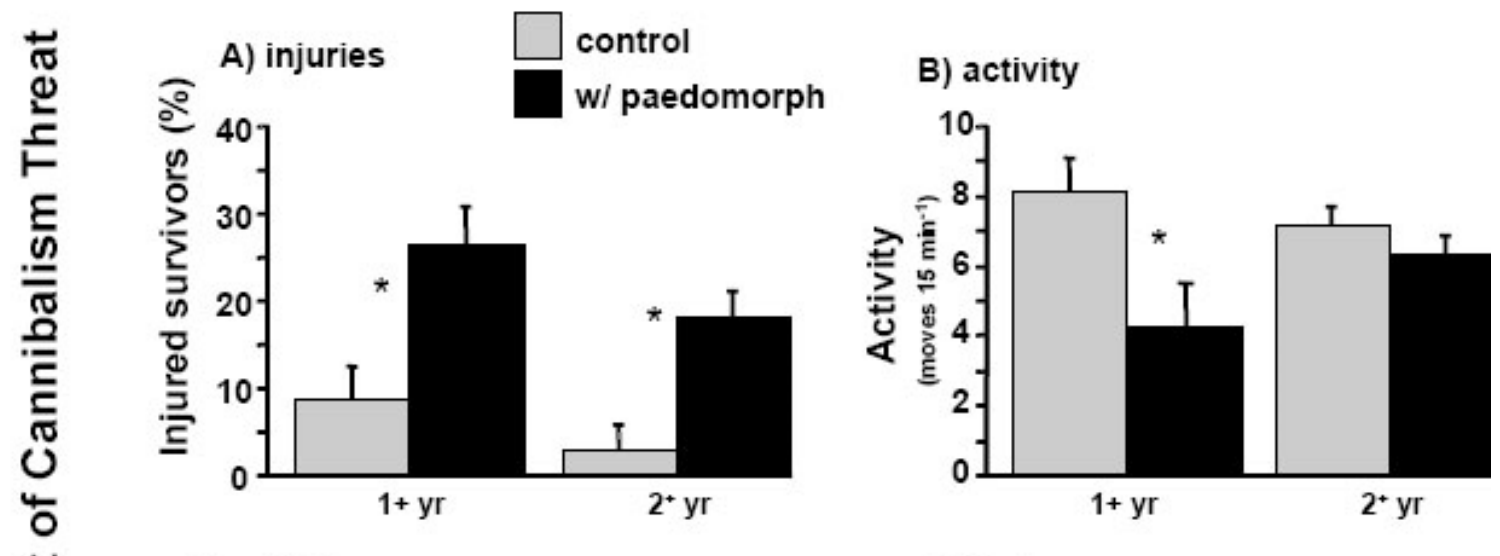

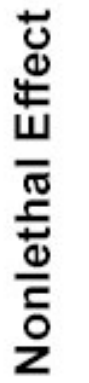

C) gut fullness

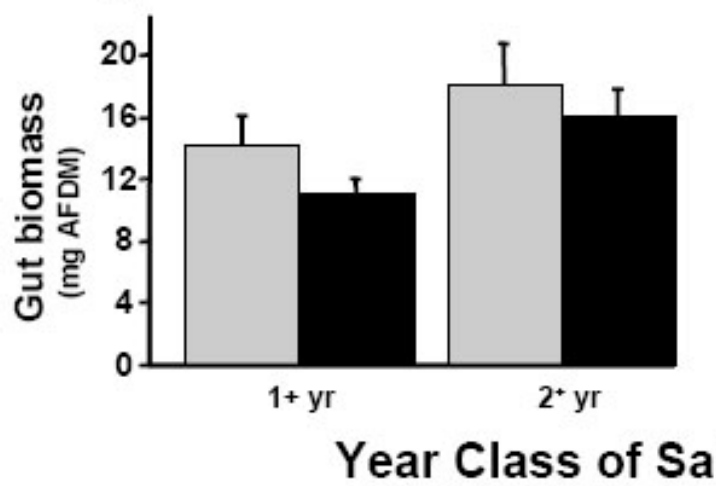

D) body mass

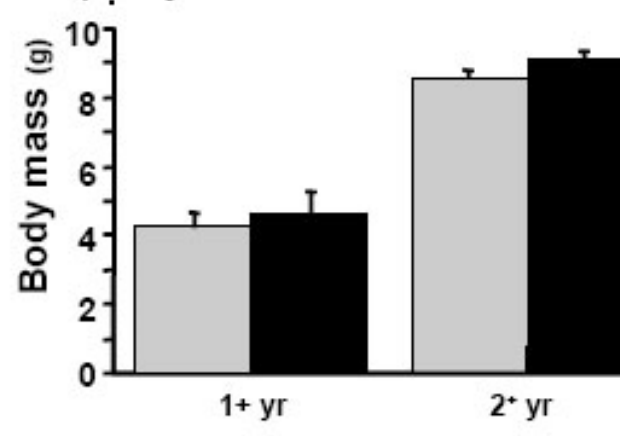

FIG. C1. Experiment 1. Non-consumptive effects of the presence of paedomorphs on 1+ and 2+ yr larvae. Asterisl difference between cannibal and control treatments based on Tukey’s post hoc comparison of means for significant c 
Experiment 2) Nonconsumptive effects of paedomorphs on YOY larvae.

$\begin{array}{lcccc}\begin{array}{lcc}\text { a) } \% \text { injured } \\ \text { presence of cannibal }\end{array} & 1 & 0.74 & 13.1 & 0.002 * \text { value } \\ \text { prey size class } & 1 & 0.09 & 1.7 & 0.21 \\ \text { cannibal } \times \text { size class } & 1 & 0.09 & 1.7 & 0.21 \\ \text { error } & 16 & 0.06 & & \end{array}$

$\begin{array}{lcccc}\text { b) activity rates } & \text { df } & \text { mss } & F \text { value } & P \text { value } \\ \text { presence of cannibal } & 1 & 31.2 & 16.6 & 0.0009 * \text { * } \\ \text { prey size class } & 1 & 3.7 & 1.9 & 0.18 \\ \text { cannibal } \times \text { size class } & 1 & 2.5 & 1.4 & 0.26 \\ \text { error } & 16 & 1.9 & & \end{array}$

$\begin{array}{llll}\text { c) gut fullness } & \text { df } & \text { mss } & P \text { value }\end{array}$

$\begin{array}{lcccc}\text { presence of cannibal } & 1 & 15.9 & 15.0 & 0.001 * \\ \begin{array}{lccc}\text { prey size class } \\ \text { cannibal } \times \text { size class }\end{array} & 1 & 3.5 & 3.3 & 0.09 \\ \text { error } & 16 & 1.1 & 0.8 & 0.39\end{array}$

d) final larval mass $\quad$ df mss $F$ value $P$ value

$\begin{array}{lcccc}\text { presence of cannibal } & 1 & 1.6 & 14.4 & 0.002 * \\ \text { prey size class } & 1 & 10.5 & 97.5 & <0.0001 * \\ \text { cannibal } \times \text { size class } & 1 & 0.5 & 4.5 & 0.06 \\ \text { error } & 16 & 0.11 & & \end{array}$

Graphical results of treatment means presented in the main article as Fig. 2. 
Experiment $3.3^{+}$yr larvae cannibals and three size classes of smaller larvae

\begin{tabular}{|c|c|c|c|c|}
\hline a) $\%$ injured & df & mss & $F$ value & $P$ value \\
\hline presence of cannibal & 1 & 8664.0 & 67.1 & $<0.0001 *$ \\
\hline prey size class & 2 & 3947.5 & 30.5 & $<0.0001 *$ \\
\hline cannibal $\times$ size class & 2 & 2647.5 & 20.5 & $<0.0001 *$ \\
\hline error & 21 & 129.1 & & \\
\hline b) activity rates & df & mss & $F$ value & $P$ value \\
\hline presence of cannibal & 1 & 30.5 & 8.9 & $0.006 *$ \\
\hline prey size class & 2 & 80.1 & 11.8 & $0.0004 *$ \\
\hline cannibal $\times$ size class & 2 & 19.6 & 2.8 & 0.08 \\
\hline error & 21 & 3.4 & & \\
\hline c) gut fullness & df & mss & $F$ value & $P$ value \\
\hline presence of cannibal & 1 & 5.5 & 3.7 & 0.07 \\
\hline prey size class & 2 & 66.5 & 45.1 & $<0.0001 *$ \\
\hline cannibal $\times$ size class & 2 & 0.3 & 0.2 & 0.85 \\
\hline error & 21 & 1.4 & & \\
\hline d) final larval mass & df & mss & $F$ value & $P$ value \\
\hline presence of cannibal & 1 & 0.62 & 14.7 & $0.001 *$ \\
\hline prey size class & 2 & 7.5 & 177.9 & $<0.0001 *$ \\
\hline cannibal $\times$ size class & 2 & 0.2 & 2.8 & 0.08 \\
\hline error & 21 & 0.04 & & \\
\hline
\end{tabular}

Graphical results of treatment means presented in the main article as Fig. 3. 


\section{Ecological Archives E091-039-A4}

Scott A. Wissinger, Howard H. Whiteman, Mathieu Denoël, Miranda L. Mumford, and Catherine B. Aubee. 2010. Consumptive and nonconsumptive effects of cannibalism in fluctuating age-structured populations. Ecology 91:549-559.

Appendix D. Dietary data for cannibals and victims in three mesocosm experiments on tiger salamander cannibalism. The data were first analyzed using a two-way MANOVA for the effects of cannibal presence and size of potential conspecific victims on diet. Because there was no or weak evidence for cannibal-induced niche shifts in any of the size classes of victims, we combined the victim data from tanks with and without cannibals within the three experiments for comparison to the cannibal diets in part 2 below.

1. Two-way MANOVAs on four categories of prey (large invertebrates, chironomids, microcrustaceans, and terrestrials + miscell the diets of potential victims.
Experiment
Wilks' $\lambda$
$F$ value
$P$ value

1) Paedomorphs on age $1^{+}$and $2^{+}$yr larvae (df 4, 21)

Presence of cannibal

Victim size

0.503

Cannibals $\times$ victim size

0.949
0.9

0.957

0.617

0.962
Cannibal $\times$ prey size

3) Cannibalism by $3^{+}$yr larvae on three size classes of larvae $(8,36)$
0.716

0.131
1.8

7.9
0.49

$0.004 *$

0.88
Victim size

Cannibal $\times$ victim size

2. One-way MANOVA and protected ANOVAs comparing diets of cannibals and victims in mesocosm cannibalism experiments

a) Diets of paedomorphic adult tiger salamanders and age $1^{+}$and $2^{+}$yr larvae used as potential victims.

\begin{tabular}{|c|c|c|c|c|c|}
\hline MANOVA & (df 8,60$)$ & & ANOVAs & (df 2,33 & \\
\hline Wilks' $\lambda$ & $F$ value & $P$ value & & $F$ value & $P$ value \\
\hline 0.32 & 5.7 & $<0.0001$ & Large Inverts & 10.2 & 0.0004 \\
\hline & & & Chironomids & 4.5 & 0.012 \\
\hline & & & Microcrustaceans & 10.5 & 0.0003 \\
\hline & & & Terrestrial /Misc. & 5.6 & 0.0083 \\
\hline
\end{tabular}




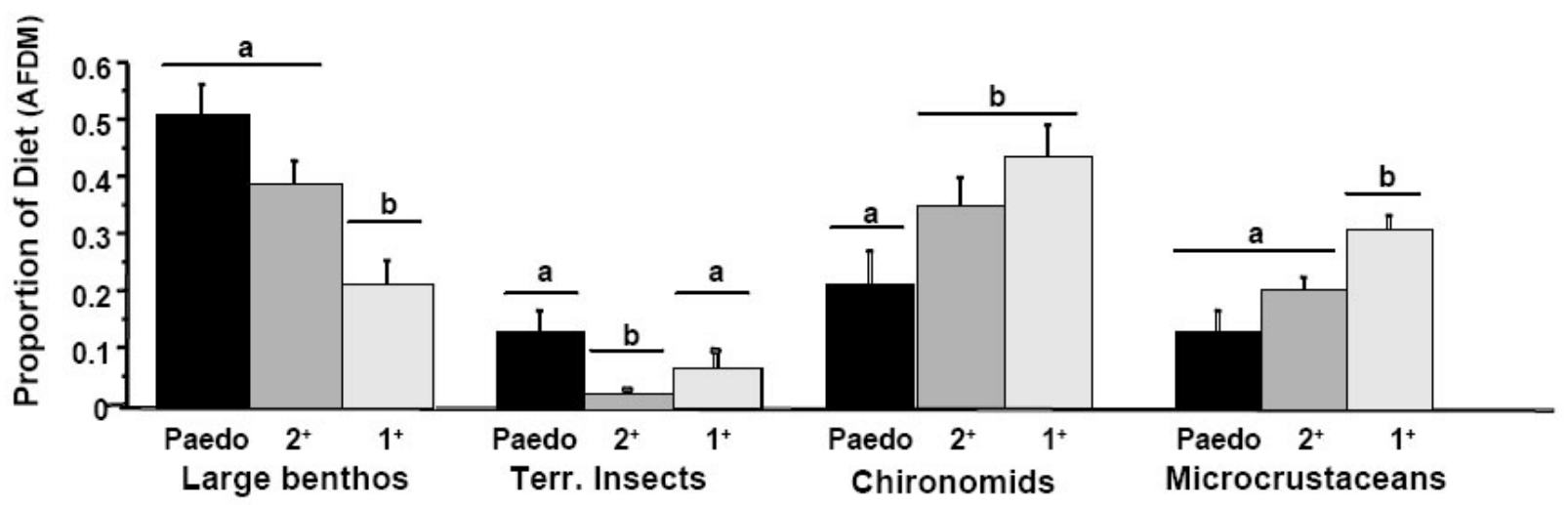

FIG. D1. Comparative diets of tiger salamander size combinations (paedomorphic adults and age 2+ and 1+ yr larvae) in mesocosm cannibalism experiments. Bars with lower case letters indicate groups of means that do not differ based on Tukey's post hoc tests for significant ANOVA results (above).

b) Diets of paedomorphic adult tiger salamanders and two size of YOY larvae used as potential victims

MANOVA (df 8,54)

Wilks' $\lambda \quad F$ value $\quad P$ value

$0.054 \quad 22.3 \quad<0.001$
ANOVAs (df 2,30)

$F$ value

$P$ value

Large Inverts

42.9

$<0.001$

Chironomids

25.4

$<0.001$

Microcrustaceans

62.5

$<0.001$

Terrestrial /Misc. $\quad 7.6$

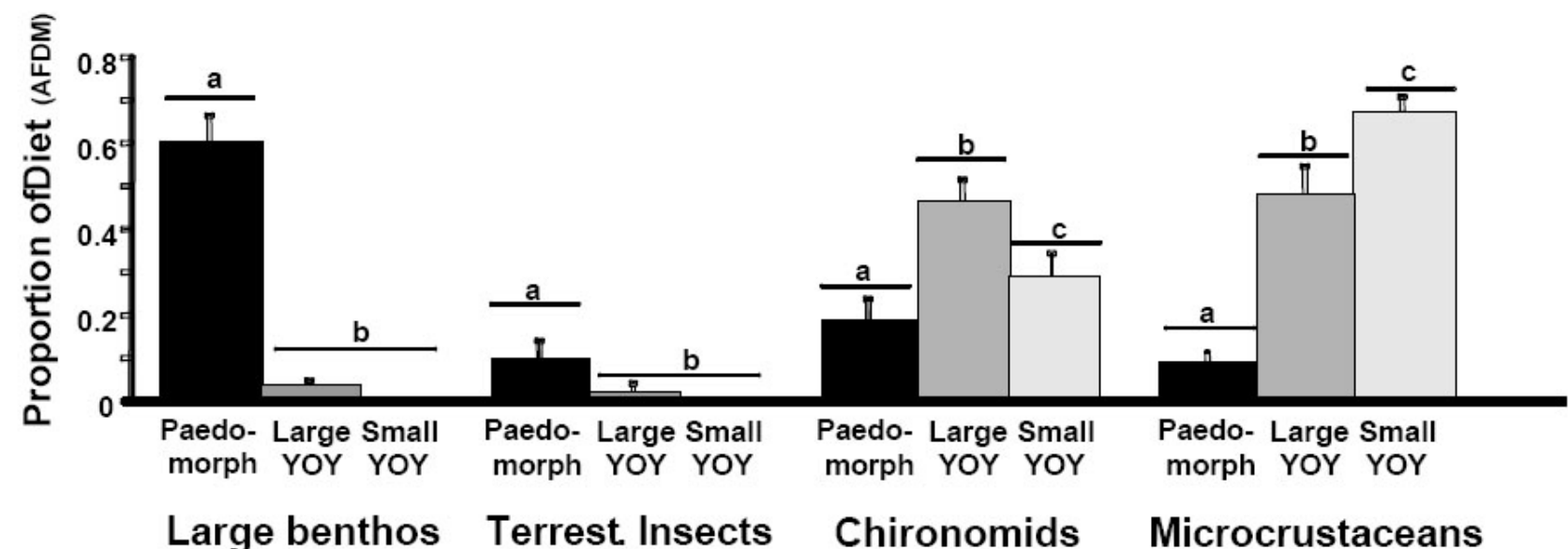

FIG. D2. Comparative diets of tiger salamander size combinations (paedomorphic adults and two size classes of YOY larvae) in mesocosm cannibalism experiments. Bars with lower case letters indicate groups of means that do not differ based on Tukey's post hoc tests for significant ANOVA results (above). 
c) Diets of paedomorphic adult tiger salamanders and three size classes of potential victims

MANOVA (df 12,93)

Wilks' $\lambda \quad F$ value $P$ value

0.063

14.2

$<0.001$

Large Inverts

Chironomids

Microcrustaceans

Terrestrial /Misc.
$F$ value

$P$ value

42.9

21.9

27.1

3.2

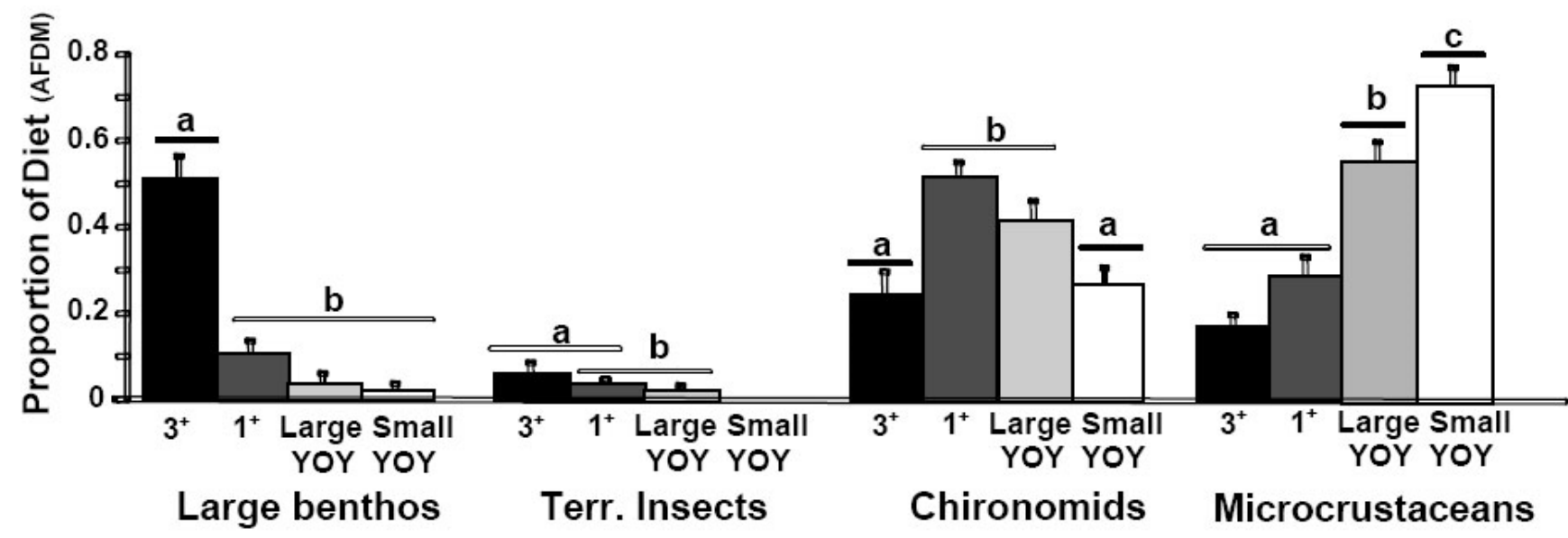

FIG. D3. Comparative diets of tiger salamanders (age 3+ yr, 1+ yr, and two sizes of YOY larvae) in mesocosm cannibalism experiments. Bars with lower case letters indicate groups of means that do not differ based on Tukey's post hoc tests for significant ANOVA results (above) 